\title{
A synbiotic containing Lactobacillus acidophilus CHO-220 and inulin improves irregularity of red blood cells
}

\author{
L.-G. Ooi, ${ }^{*}$ R. Bhat, ${ }^{*}$ A. Rosma, ${ }^{*}$ K.-H. Yuen, $\dagger$ and M.-T. Liong*1 \\ *School of Industrial Technology, and \\ †School of Pharmaceutical Sciences, Universiti Sains Malaysia, 11800 Penang, Malaysia
}

\begin{abstract}
This randomized, double-blind, placebo-controlled, and parallel-design study was conducted to investigate the effect of a synbiotic product containing Lactobacillus acidophilus $\mathrm{CHO}-220$ and inulin on the irregularity in shape of red blood cells (RBC) in hypercholesterolemic subjects. The subjects $(\mathrm{n}=32)$ were randomly allocated to 2 groups, a treatment group (synbiotic product) and a control group (placebo), and received 4 capsules of either synbiotic or placebo daily for $12 \mathrm{wk}$. Morphological representation via scanning electron microscopy showed that the occurrence of spur RBC was improved upon supplementation of the synbiotic. In addition, the supplementation of synbiotic reduced the cholesterol:phospholipids ratio of the RBC membrane by $47.02 \%$ over 12 wk, whereas the control showed insignificant changes. Our present study also showed that supplementation of the synbiotic reduced the concentration of saturated fatty acids (SFA), increased unsaturated fatty acids (UFA), and increased the ratio of UFA:SFA over $12 \mathrm{wk}$, whereas the control showed inconspicuous changes. The alteration of RBC membrane was assessed using fluorescence anisotropy (FAn) and fluorescence probes with different affinities for varying sections of the membrane phospholipid bilayer. A noticeable decrease in FAn of three fluorescent probes was observed in the synbiotic group compared with the control over $12 \mathrm{wk}$, indicative of increased membrane fluidity and reduced cholesterol enrichment in the RBC membrane.
\end{abstract}

Key words: Lactobacillus acidophilus, inulin, cholesterol/phospholipids, spur red blood cell

\section{INTRODUCTION}

Hypercholesterolemia is a metabolic derangement characterized by the presence of high levels of cholesterol in the blood, which can lead to many forms of diseases, most remarkably cardiovascular diseases (Austin et al.,

Received April 8, 2010.

Accepted June 4, 2010.

${ }^{1}$ Corresponding author: mintze.liong@usm.my
2004). Cardiovascular disease is one of the most prevalent diseases in developing countries and urgency for its management is increasing as the incidence in these countries grows each year (Reddy and Yusuf, 1998). In 2003, according to the World Health Organization, cardiovascular disease made up 16.7 million or $29.2 \%$ of total global deaths and will be the leading cause of death in developing countries by 2010 (WHO, 2003). High blood cholesterol levels can be reduced by medication, exercise, or dietary modification (Neuhouser et al., 2002).

Past studies have associated cholesterol-enriched diets with hypercholesterolemia, which in turn causes morphological abnormalities in red blood cells (RBC) leading to their decreased life span (Nayak et al., 2008). Such abnormalities can subsequently increase the risk of impairing the physical function and microcirculation of $\mathrm{RBC}$. In RBC, the membrane phospholipids are asymmetrically arranged into a lipid bilayer with a thickness of 2 molecules, and cholesterol is intercalated between the phospholipid molecules (Mohandas and Gallagher, 2008). Cholesterol is one of the main lipid components of RBC membranes in all mammalian cells, such that the ratio of cholesterol:phospholipids may play a role in changes in the lipid composition in the membrane fraction (Byfield et al., 2004). The cholesterol:phospholipids ratio dictates the fluid properties of RBC membrane. Altered composition could affect the physical properties of the membrane lipid bilayer, including changes in membrane fluidity and subsequently membrane deformability (Berlin et al., 1998). Abnormal alterations in $\mathrm{RBC}$ membrane have been reported in patients with hypercholesterolemia (Cooper et al., 1980). Cholesterol accumulation in RBC membranes has been observed in animals and humans with hypercholesterolemia (Waldeck et al., 1995; López-Revuelta et al., 2005). These studies demonstrated that diet-induced hypercholesterolemia simultaneously generated cholesterol enrichment in the RBC membranes, leading to the development of spur (a sharp, horny, star-like shape) RBC that affected membrane fluidity.

Interestingly, dietary modifications with probiotics or prebiotics have been demonstrated to lower serum 
cholesterol levels in animal models such as rats (Liong and Shah, 2006) and pigs (Liong et al., 2007). Probiotics are "living microbial supplements that beneficially affect the host animals by improving its intestinal microbial balances" (FAO/WHO, 2001). Prebiotics are "indigestible fermented food substrates that selectively stimulate the growth, composition and activity of microflora in gastrointestinal tract and thus improve hosts' health and well-being" (Roberfroid, 2007). When probiotics and prebiotics are used in combination, they are known as synbiotics. In addition to improving gut health, synbiotics have been reported to exert other health-promoting effects such as simulation of the immune system (Schley and Field, 2002; Galdeano et al., 2007), antihypertensive effects (Yeo and Liong, 2010), prevention of cancer (Hirayama and Rafter, 2000; Klinder et al., 2004), and facilitation of mineral absorption (Scholz-Ahrens et al., 2007). In the interest of these promising effects, much work has emphasized the incorporation of synbiotics into milk products for human consumption. Milk products have a long history of safe use as carriers for synbiotics because of the $\mathrm{pH}$ and buffering capacity of milk products that safeguard the viability of probiotics during storage and transit along the harsh human gastrointestinal tract (Ooi et al., 2010).

Considering that past studies have reported positive effects of probiotics, prebiotics, and synbiotics on serum cholesterol (Nguyen et al., 2007; Zhang et al., 2007; Wong et al., 2010), we hypothesized that these supplements could also positively improve irregularities of RBC. Although much positive evidence has surfaced on the use of the probiotics, prebiotics, and synbiotics to reduce blood cholesterol levels, to our knowledge, no attempt has been made to evaluate their effects on irregularities of RBC in humans. Thus, the aim of this study was to investigate the effect of a synbiotic containing Lactobacillus acidophilus CHO-220 and inulin on irregularities of shape of RBC in hypercholesterolemic subjects. Morphology of RBC, ratio of cholesterol:phospholipids, membrane fluidity properties, and fatty acid profiles of $\mathrm{RBC}$ were investigated.

\section{MATERIALS AND METHODS}

\section{Source of Probiotic Culture and Prebiotic}

Lactobacillus acidophilus CHO-220 is a humanderived strain that was obtained from the Bioprocess Technology Culture Collection Center (Universiti Sains Malaysia, Penang, Malaysia). The stock culture was stored at $-20^{\circ} \mathrm{C}$ in $40 \%$ (vol/vol) sterile glycerol. The probiotic culture was cultured 3 times in sterile de Man-Rogosa-Sharpe (MRS) broth (Hi-Media, Mumbai,
Maharashtra, India) supplemented with $0.15 \%$ (wt/vol) L-cysteine hydrochloride (Hi-Media) before experimental use. Cultures were inoculated using a $1 \%$ (vol/vol) inoculum of L. acidophilus CHO-220 and the culture was incubated for $24 \mathrm{~h}$ at $37^{\circ} \mathrm{C}$ before use and stored at $4^{\circ} \mathrm{C}$ between transfers. A freeze-dried culture (containing approximately $10^{10} \mathrm{cfu} / \mathrm{g}$ ) was used in the present study. For freeze-drying, the cell pellet of $L$. acidophilus CHO-220 obtained from harvesting the fermentation broth was suspended in $2.0 \%$ (wt/vol) of food-grade cryoprotectant pectin (Unipectine RS 150, Specialty Point Sdn. Bhd., Selangor, Malaysia) at a ratio of 1:1, frozen at $-20^{\circ} \mathrm{C}$, and freeze-dried at $-40^{\circ} \mathrm{C}$ and 13.3 $\mathrm{Pa}$. A commercially available prebiotic, inulin (Raftiline ST, Orafti Pty. 153 Ltd., Tienen, Belgium) was used. The probiotic culture was produced under certified good laboratory practice (GLP) and good manufacturing practice (Malaysian Pharmaceutical Industries Sdn. Bhd., Bayan Lepas, Penang, Malaysia).

\section{Production of Synbiotic Capsules}

Synbiotic capsules were produced by Polens (M) Sdn. Bhd. (Shah Alam, Selangor, Malaysia) under good manufacturing practice conditions. The capsules produced were subsequently bottled, sealed, and stored at $4^{\circ} \mathrm{C}$. The capsules were cultured and tested for the viability of L. acidophilus CHO-220 before and at the end of the trial. Each synbiotic capsule contained $9 \mathrm{log} \mathrm{cfu} / \mathrm{g}$ of L. acidophilus CHO-220 and $0.20 \mathrm{~g}$ of inulin, and the placebo capsules contained rice starch (Alagappa Flour Mills Sdn. Bhd., Penang, Malaysia).

\section{Selection of Subjects}

Subjects were screened and requested to complete a 3-d dietary diary. The dietary data and screening laboratory results were assessed against the exclusion criteria, and those who met the inclusion criteria were randomized to 1 of 2 treatment arms, namely the treatment group (synbiotic product) or the control group (placebo).

Subjects were recruited based on the following inclusion criteria: total plasma cholesterol concentration of $\geq 5.20 \mathrm{mmol} / \mathrm{L}$ and $\leq 6.20 \mathrm{mmol} / \mathrm{L}$ and a low density lipoprotein level of $\leq 4.2 \mathrm{mmol} / \mathrm{L}$; not taking lipidlowering medication; without myocardial infarction, angioplasty, or stroke within the last $3 \mathrm{mo}$; without diabetes and/or were not on diabetic medication; without glucose intolerance; without hepatic and/or renal failure and/or were not on medications related to heart disease, hepatic or renal disease; were not treated with anticoagulants, immunosuppressant, corticosteroids or estrogens; and had no history of thyroid replacement. 
Exclusion criteria included medical history (including known history of major hematological, renal, cardiovascular, or hepatic abnormalities) or physiological condition; social circumstances that would impair reliable participation in the trial; increased risk to oneself or others by participating; female subjects who were pregnant, nursing or with a positive urine pregnancy test or who were intending to become pregnant within 3 mo after completion of the trial; age below 18 years; recent history of alcohol abuse; immunocompromised individuals; and subjects who, in opinion of the investigator, were not likely to complete the trial for whatever reason.

\section{Study Protocol}

This study was conducted according to the guidelines laid down in the Declaration of Helsinki, and all procedures involving human subjects were approved by the Joint Ethics Committee of School of Pharmaceutical Sciences-Universiti Sains Malaysia, Hospital Lam Wah Ee (Penang). Written informed consent was obtained from all subjects. Subjects $(\mathrm{n}=32)$ were randomly divided into 2 groups of 16 each. The treatment group was given synbiotic capsules and the control group was given placebo capsules. Each subject took 4 capsules daily ( 2 in the morning and 2 in the evening) of either synbiotic or placebo for a period of 12 wk.

Fasting blood samples were collected at wk 0, 6, and 12 of the trial into tubes containing lithium heparin, and $\mathrm{RBC}$ were separated by centrifugation for $15 \mathrm{~min}$ at 550 $\times g$ at $15^{\circ} \mathrm{C}$. The samples of RBC were then processed for analyses. Assessment of BW was conducted at wk 0, 6 , and 12 of the trial and subjects were also contacted weekly by telephone to ascertain if any adverse effects were experienced. All subjects were advised to maintain their usual dietary habits (except probiotic-containing foods and cholesterol-lowering medication), and food intake was monitored using a 3 -d food diary.

\section{Analyses}

The RBC count was performed using a Neubauer hemocytometer (Hirschmann Laborgeräte, Eberstadt, Germany). A scanning electron microscopy procedure was used to examine the morphology of RBC as described previously (Glauert, 1980; Nation, 1983; Dykstra, 1992). Samples of RBC were suspended in McDowellTrump fixative $[4 \%(\mathrm{vol} / \mathrm{vol})$ of formaldehyde; $1 \%$ ( $\mathrm{vol} /$ vol) of glutaraldehyde, Sigma-Aldrich, St. Louis, MO] overnight (McDowell and Trump, 1976). The sample was centrifuged for $1 \mathrm{~min}$ at $300 \times g$ at $25^{\circ} \mathrm{C}$ and the pellet was resuspended in $0.1 M$ phosphate buffer (pH 7.2) containing 1\% (wt/vol) of osmium tetroxide (Sigma-Aldrich) for $1 \mathrm{~h}$ at $25^{\circ} \mathrm{C}$. The pellet was then washed twice with distilled water and the sample was dehydrated by resuspending the pellet with $50 \%, 75 \%$, $95 \%$, and $100 \%$ (vol/vol) ethanol and hexamethyldisilazane (ProSci Tech, Thuringowa Central, Australia), respectively, for $10 \mathrm{~min}$ at $25^{\circ} \mathrm{C}$. Hexamethyldisilazane was decanted from the tube and the residue was airdried at $25^{\circ} \mathrm{C}$. The dried cells were then mounted onto a scanning electron microscopy specimen stub, coated with gold in a sputter coater (Polaran, Walford, UK) for $5 \mathrm{~min}$, and examined under the scanning electron microscope (Leo Supra 50 VP Field Emission SEM, Carl-Ziess SMT, Oberkochen, Germany) equipped with Oxford INCA 400 energy dispersive $\mathrm{x}$-ray microanalysis system (Oxford Instruments Analytical, Bucks, UK).

The RBC (ghost) membranes were obtained as described previously (Huel et al., 2008). The RBC samples were washed with $0.5 \mathrm{~mL}$ of isotonic Tris- $\mathrm{HCl}$ buffer ( $\mathrm{pH}$ 6.0) to remove the buffy coat. The washed cells were then resuspended in $0.5 \mathrm{~mL}$ of isotonic Tris- $\mathrm{HCl}$ buffer $(\mathrm{pH} \mathrm{7.4)}$ and centrifuged at 8,000 $\times g$ for $20 \mathrm{~min}$ at $4^{\circ} \mathrm{C}$ for several times until the membranes appeared colorless to the naked eye. The last colorless pellet was then rinsed twice with $0.5 \mathrm{~mL}$ of Tris- $\mathrm{HCl}$ buffer $(\mathrm{pH}$ 7.4) and collected as RBC ghost for further analyses.

The membrane lipid order of RBC was determined via fluorescence anisotropy (FAn). Fluorescent probes were inserted into the membrane of RBC (ghost) membranes; namely 1,6-diphenyl-1,3,5-hexatriene (DPH; Sigma-Aldrich), 1-(4-trimethylammonium)-6phenyl-1,3,5hexatriene (TMA-DPH; Sigma-Aldrich), and 8-anilino-1-napthalenesulfonic acid (ANS; SigmaAldrich). All probes were prepared according to Liong et al. (2007). The membranes of RBC with an optical density of 0.3 were suspended in probe solutions at a ratio of $3: 1$ and incubated at $37^{\circ} \mathrm{C}$. Fluorescence anisotropy was measured using a fluorescence spectrophotometer (Cary Eclipse, Varian, Palo Alto, CA). Excitation wavelength was $365 \mathrm{~nm}$ for DPH and TMA-DPH and $390 \mathrm{~nm}$ for ANS. Emission was determined at $445 \mathrm{~nm}$ for DPH and TMA-DPH and $490 \mathrm{~nm}$ for ANS. Unlabeled membrane of RBC was used as a blank.

The lipids were extracted from the RBC membrane as described previously (Nayak et al., 2008). The RBC ghosts were suspended in $1 \mathrm{~mL}$ of methanol and homogenized. Chloroform $(2 \mathrm{~mL})$ was then added to the homogenized sample and centrifuged at $550 \times g$ for 10 min at $15^{\circ} \mathrm{C}$. The upper aqueous layer was aspirated and discarded while the lower layer was retained for lipid testing. Aliquots of this layer were used for the determination of cholesterol and phospholipids using commercially enzymatic kits (bioMérieux Corporation, Marcy l'Etoile, France).

The lipids in membranes of RBC were also converted into fatty acid methyl esters (FAME) as described 
Table 1. Mean age (mean values $\pm \mathrm{SD}$ ) and sex of hypercholesterolemic subjects $(\mathrm{n}=32)$ recruited for the study

\begin{tabular}{lcl}
\hline Treatment & Age $(\mathrm{yr})$ & Sex \\
\hline Control & $36.9 \pm 13.4^{\mathrm{A}}$ & 10 male and 6 female \\
Synbiotic & $31.5 \pm 10.4^{\mathrm{A}}$ & 8 male and 8 female \\
\hline
\end{tabular}

${ }^{\mathrm{A}, \mathrm{B}}$ Means in the same column with different uppercase superscripts are significantly different $(P<0.05)$.

previously (Kang and Wang, 2005) and quantified using gas chromatography (GC-17A, Shidmazu, Kyoto, Japan). The GC was equipped with a capillary column $(30 \mathrm{~m} \times 0.25 \mathrm{~mm}$ inside diameter $\times 0.39 \mathrm{~mm}$ outside diameter; Varian FactorFour, Walnut Creek, CA), and the oven temperature was held at $100^{\circ} \mathrm{C}$ after sample injection and increased to $225^{\circ} \mathrm{C}$ at a rate of $5^{\circ} \mathrm{C} / \mathrm{min}$. The injector and detector temperatures were $260^{\circ} \mathrm{C}$ and $280^{\circ} \mathrm{C}$, respectively. Helium was used as the carrier gas $(3 \mathrm{~mL} / \mathrm{min})$, split ratio was 1:100, and the injection volume was $1 \mu \mathrm{L}$. The concentration of FAME in samples was determined using a standard of FAME (C:4 to C:24; Supelco, Bellefonte, PA).

\section{Statistical Analysis}

The determination of sample size was based on total cholesterol. To demonstrate a difference in population means of $1.26 \mathrm{mmol} / \mathrm{L}$, standard deviation of 0.93 $\mathrm{mmol} / \mathrm{L}$, an $\alpha$ error of $5 \%$, and a power of $95 \%$ (Liong et al., 2007), a minimum total of 30 subjects was required for this study. Data analysis was performed using a split-plot design. Factorial design with block-treatment confounding was used for time-based analyses. The layout of the type SPF-2.4 design was used to evaluate the significant differences between sample means, with the significance level at $\alpha=0.05$. Mean comparisons were also assessed by the same factorial design using ANOVA for Simple Effects (Kirk, 1968).

\section{RESULTS AND DISCUSSION}

\section{$B W$ and Dietary Intake}

All 32 subjects completed the treatment protocol and did not show any adverse effects. Their entry character- istics at baseline are summarized in Table 1 . There was no significant $(P>0.05)$ difference in BW and body mass index between the treatment and control groups over the 12-wk period (Table 2). Energy and nutrient intake, as calculated based on the Nutrient Composition of Malaysian Foods (Tee et al., 1997), was also constant and did not change significantly $(P>0.05)$ between the 2 groups over the study (Table 3 ). There were no changes in consumption of carbohydrate, protein, fat, or cholesterol in either group between baseline and the end of the study $(P>0.05)$.

\section{Scanning Electron Microscopy}

Hypercholesterolemia has been associated with atherosclerosis. Generally, a diet high in cholesterol contributes to the induction of hypercholesterolemia. Past studies reported that an excessive intake of dietary cholesterol produced elevated serum cholesterol levels accompanied by changes in RBC morphology. Excess cholesterol is transferred to the RBC leading to morphological changes and an increase in the cholesterol:phospholipids ratio of the RBC membrane (Waldeck et al., 1995). With the feeding of a high cholesterol diet, the cholesterol content of the RBC increases progressively, leading to the development of a large number of spur cells (López-Revuelta et al., 2005). Cooper et al. (1980) previously discovered a significant abnormality of RBC morphology (occurrence of spur RBC) in hypercholesterolemic-induced dogs. In the study, the authors demonstrated that a cholesterolenriched diet caused profound and reversible changes in lipid composition, membrane fluidity, and morphology of red cells in dogs. Liong et al. (2007) also previously reported the occurrence of spur RBC in diet-induced hypercholesterolemic pigs, and a synbiotic product (containing L. acidophilus ATCC 4962, fructooligosaccharides, mannitol, and inulin) reduced the occurrence of spur RBC in hypercholesterolemic pigs at the end of the study compared with the control. To date, no attempt has been made to evaluate the effects of the synbiotic on irregularities of RBC in humans. In the present

Table 2. Effect of the synbiotic on BW and body mass index (BMI) (mean values $\pm \mathrm{SD}$ ) of hypercholesterolemic subjects $(\mathrm{n}=32)$ for $12 \mathrm{wk}$

\begin{tabular}{llccc}
\hline & & \multicolumn{3}{c}{ Week } \\
\cline { 3 - 5 } Item & Treatment & 0 & 6 & 12 \\
\hline BW $(\mathrm{kg})$ & Control & $61.25 \pm 13.62^{\mathrm{A}, \mathrm{a}}$ & $61.06 \pm 13.06^{\mathrm{A}, \mathrm{a}}$ & $60.94 \pm 13.23^{\mathrm{A}, \mathrm{a}}$ \\
& Synbiotic & $60.78 \pm 18.86^{\mathrm{A}, \mathrm{a}}$ & $61.13 \pm 18.97^{\mathrm{A}, \mathrm{a}}$ & $61.09 \pm 19.45^{\mathrm{A}, \mathrm{a}}$ \\
BMI $\left(\mathrm{kg} / \mathrm{m}^{2}\right)$ & Control & $23.16 \pm 4.59^{\mathrm{A}, \mathrm{a}}$ & $23.01 \pm 4.42^{\mathrm{A}, \mathrm{a}}$ & $23.04 \pm 4.41^{\mathrm{A}, \mathrm{a}}$ \\
& Synbiotic & $22.76 \pm 5.68^{\mathrm{A}, \mathrm{a}}$ & $22.90 \pm 5.71^{\mathrm{A}, \mathrm{a}}$ & $22.86 \pm 5.82^{\mathrm{A}, \mathrm{a}}$ \\
\hline
\end{tabular}

${ }^{\mathrm{A}, \mathrm{B}}$ Means in the same column with different uppercase superscripts are significantly different $(P<0.05)$.

${ }^{\mathrm{a}, \mathrm{b}}$ Means in the same row with different lowercase superscripts are significantly different $(P<0.05)$. 
Table 3. Energy and nutrient intake (mean values $\pm \mathrm{SD})$ of hypercholesterolemic subjects $(\mathrm{n}=32)$ for 12 wk

\begin{tabular}{llrrr}
\hline & & \multicolumn{3}{c}{ Week } \\
\cline { 3 - 5 } Item & Treatment & \multicolumn{1}{c}{0} & \multicolumn{1}{c}{12} \\
\hline Energy $(\mathrm{kcal} / \mathrm{d})$ & Control & $2,001.70 \pm 615.78^{\mathrm{A}, \mathrm{a}}$ & $2,003.31 \pm 612.86^{\mathrm{A}, \mathrm{a}}$ & $2,004.19 \pm 617.45^{\mathrm{A}, \mathrm{a}}$ \\
& Synbiotic & $2,201.74 \pm 639.95^{\mathrm{A}, \mathrm{a}}$ & $2,192.49 \pm 632.12^{\mathrm{A}, \mathrm{a}}$ & $2,196.69 \pm 639.80^{\mathrm{A}, \mathrm{a}}$ \\
Carbohydrates $(\mathrm{g} / \mathrm{d})$ & Control & $262.25 \pm 82.46^{\mathrm{A}, \mathrm{a}}$ & $264.88 \pm 85.50^{\mathrm{A}, \mathrm{a}}$ & $265.64 \pm 87.67^{\mathrm{A}, \mathrm{a}}$ \\
& Synbiotic & $282.39 \pm 87.68^{\mathrm{A}, \mathrm{a}}$ & $283.36 \pm 87.61^{\mathrm{A}, \mathrm{a}}$ & $284.56 \pm 86.45^{\mathrm{A}, \mathrm{a}}$ \\
Protein $(\mathrm{g} / \mathrm{d})$ & Control & $60.39 \pm 26.23^{\mathrm{A}, \mathrm{a}}$ & $60.83 \pm 26.86^{\mathrm{A}, \mathrm{a}}$ & $60.97 \pm 25.76^{\mathrm{A}, \mathrm{a}}$ \\
& Synbiotic & $65.89 \pm 23.78^{\mathrm{A}, \mathrm{a}}$ & $66.90 \pm 24.42^{\mathrm{A}, \mathrm{a}}$ & $66.21 \pm 23.08^{\mathrm{A}, \mathrm{a}}$ \\
Fat $(\mathrm{g} / \mathrm{d})$ & Control & $129.24 \pm 72.9^{\mathrm{A}, \mathrm{a}}$ & $128.21 \pm 74.54^{\mathrm{A}, \mathrm{a}}$ & $128.56 \pm 76.52^{\mathrm{A}, \mathrm{a}}$ \\
& Synbiotic & $139.85 \pm 71.49^{\mathrm{A}, \mathrm{a}}$ & $137.93 \pm 70.02^{\mathrm{A}, \mathrm{a}}$ & $137.42 \pm 70.08^{\mathrm{A}, \mathrm{a}}$ \\
Cholesterol $(\mathrm{mg} / \mathrm{d})$ & Control & $113.92 \pm 89.23^{\mathrm{A}, \mathrm{a}}$ & $113.67 \pm 91.97^{\mathrm{A}, \mathrm{a}}$ & $113.29 \pm 91.74^{\mathrm{A}, \mathrm{a}}$ \\
& Synbiotic & $110.31 \pm 72.73^{\mathrm{A}, \mathrm{a}}$ & $111.04 \pm 71.08^{\mathrm{A}, \mathrm{a}}$ & $111.28 \pm 74.49^{\mathrm{A}, \mathrm{a}}$ \\
\hline
\end{tabular}

${ }_{\mathrm{A}, \mathrm{B}}$ Means in the same column with different uppercase superscripts are significantly different $(P<0.05)$.

${ }^{\mathrm{a}, \mathrm{b}}$ Means in the same row with different lowercase superscripts are significantly different $(P<0.05)$.

study, supplementation with the synbiotic contributed to an improvement of RBC morphology over $12 \mathrm{wk}$ compared with the control (Figure 1) in hypercholesterolemic subjects. Our results showed that the synbiotic product reduced the occurrence of spur RBC at the end of the study compared with the control. Spur RBC are formed due to cholesterol enrichment of the RBC membrane. Cholesterol alters the shape-related properties of RBC via mechanical deformation and causes permanent transformation of $\mathrm{RBC}$ from biconcave to other shapes (Koter et al., 2004). The normal RBC membrane plays a fundamental role in the activity of deformability and thus ensures the hydrolysis of RBC every 120 d. However, the enrichment of cholesterol in RBC membrane prevents the natural deformability of $\mathrm{RBC}$, leading to hemorheological modification that could promote atherosclerosis (Martínez et al., 1996). We hypothesized that supplementation of synbiotic reduced the prevalence of spur RBC in hypercholesterolemic subjects by reducing cholesterol enrichment in the RBC membrane. Thus, we subsequently evaluated the composition of RBC membrane to better understand this possible mechanism.

\section{Ratio of Cholesterol:Phospholipids}

The concentration of cholesterol in RBC membranes of the synbiotic group decreased significantly by $21.02 \%$ $(P<0.05)$ over 12 wk, whereas the control group showed insignificant changes in cholesterol concentration (Table 4). This was accompanied by a significant $(P<0.05)$ increase in phospholipids for the synbiotic group over $12 \mathrm{wk}$. The fluidity properties of RBC membrane are often affected by the enrichment or depletion of cholesterol and the cholesterol:phospholipids ratio (Cassera et al., 2002). Cholesterol appears to maintain the bilayer matrix in an intermediate fluid state by regulating the mobility of phospholipids fatty acyl chains (Dwight et al., 1996). An increase in cholesterol relative to phospholipids has been shown to decrease the fluidity in the membranes (López-Revuelta et al., 2007). These increases might be due to an enhancement of de novo synthesis in the cell or exchange with plasma lipids or both (Shanmugasundaram et al., 1986). These changes in membrane lipid composition affect the structure and properties of $\mathrm{RBC}$, which subsequently produce abnormal shapes. Torkhovskaia et al. (1985) studied the cholesterol:phospholipids ratio of erythrocyte membranes in 256 patients with ischemic disease. The authors found that the cholesterol:phospholipids ratio was higher in the patients with ischemic disease compared with healthy subjects. The fluidity in the membranes was reduced corresponding to the increased ratio of cholesterol:phospholipids. In a recent study, Liong et al. (2007) reported that the normal ratio of cholesterol:phospholipids in RBC membrane for mammals was approximately 0.84 to 0.92 . In the present study, the ratio of cholesterol:phospholipids for the hypercholesterolemic subjects in the synbiotic group was normal (1.05 at wk 6 and 0.89 at wk 12), whereas that in the control group were higher than normal (1.64 at wk 6 and 1.73 at wk 12). Enrichment of cholesterol also resulted in an increase in cell surface area (Hui et al., 1980), leading to reduced membrane fluidity. The diminished fluidity of membrane led to a decrease in the ability of the cell to deform (van Gelder et al., 1996) and further contributes to the development of spur RBC (Coccia et al., 2007). The supplementation of synbiotic reduced cholesterol enrichment in $\mathrm{RBC}$ membrane and thus improved the morphology of RBC.

\section{Fatty Acid Methyl Esters}

The RBC membrane bilayer is composed of proteins, lipids, and cholesterol molecules. Thus, changes that 
occur including cholesterol enrichment would also affect the fatty acid profiles of the RBC membrane. We subsequently evaluated the fatty acid profiles of the RBC membranes of both the synbiotic and control groups via FAME analysis. In addition, alteration of fatty acids in the RBC membrane, such as saturated fatty acids (SFA) and unsaturated fatty acids (UFA), has been reported to affect membrane fluidity (Keddad et al., 1996; Berlin et al., 1998). In our present study, the composition of SFA and UFA of the RBC membrane in the control group showed insignificant changes over
12 wk (Table 5). However, the SFA of the synbiotic group decreased significantly by $19.95 \%(P<0.05)$ over $12 \mathrm{wk}$, whereas UFA were increased by $27.83 \%$ in the same period (Table 5). These changes also led to an increased ratio of UFA:SFA in the synbiotic group $(P<0.05)$ over $12 \mathrm{wk}$, whereas the control showed insignificant changes (Table 5). It has been reported that a decrease in the ratio of UFA:SFA decreases the fluidity of the RBC membrane (Tsuzuki et al., 2000). Red blood cell membrane fluidity is a crucial biophysical property that dictates the mobility and rotational
(A)

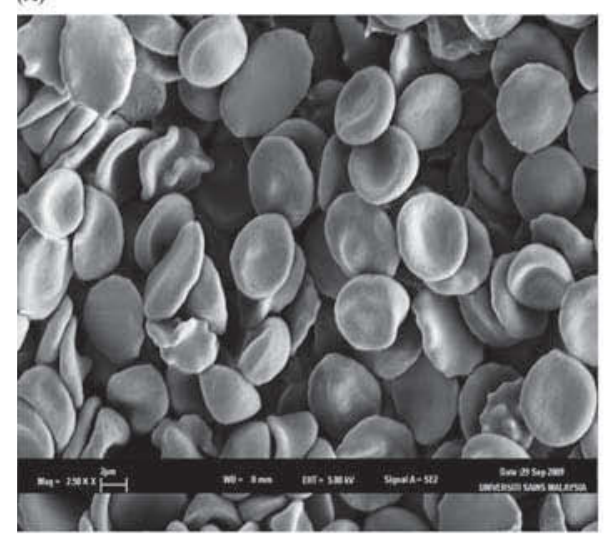

(D)

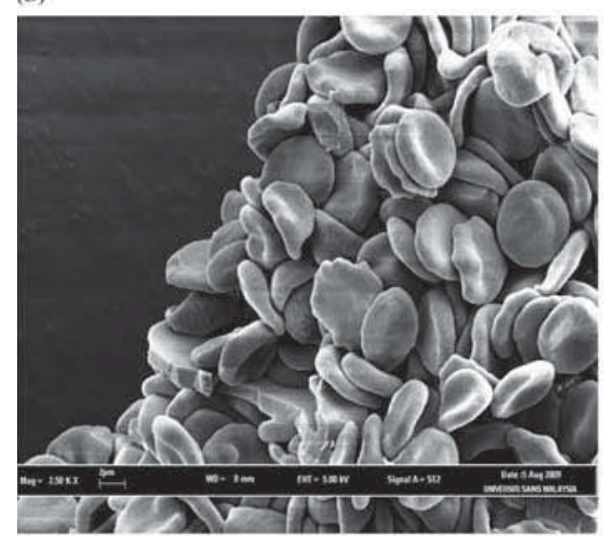

(B)

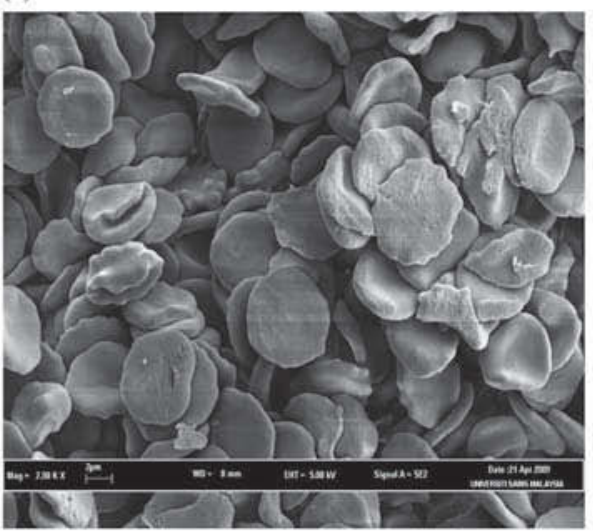

(E)

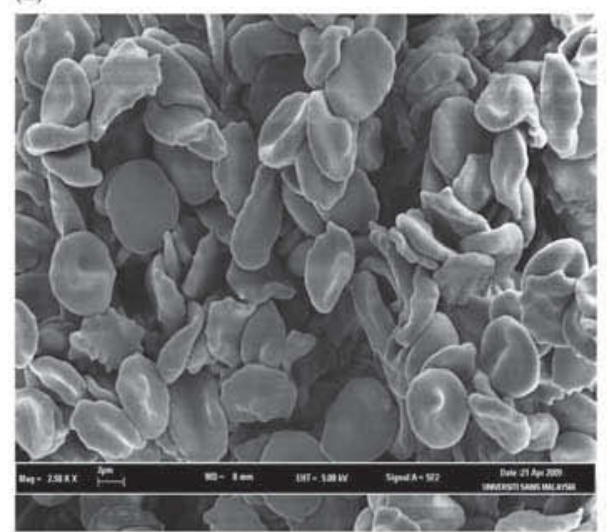

(C)

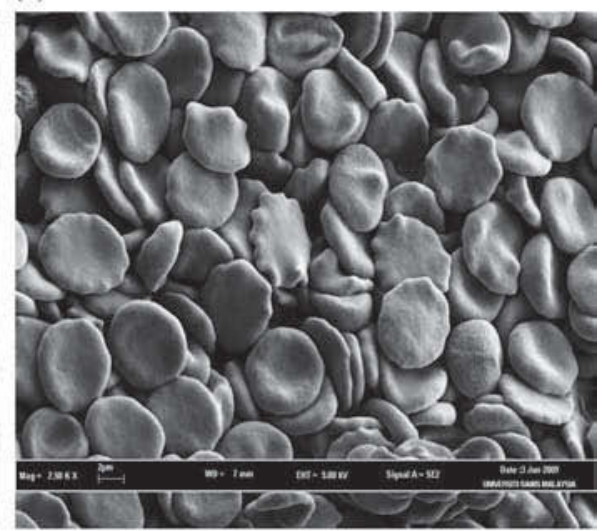

(F)

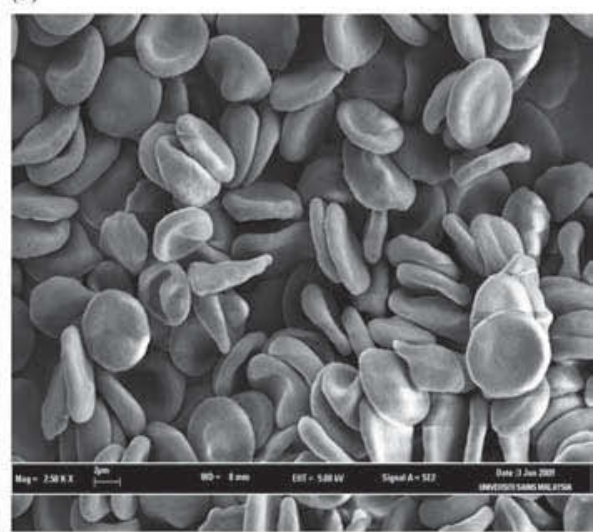

(G)

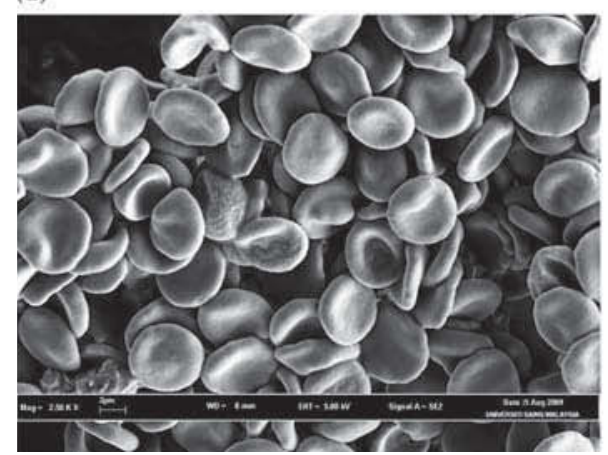

Figure 1. Red blood cells from healthy subjects (A); from subjects on the placebo at wk 0 (B), at wk 6 (C), and at wk 12 (D); and from subjects on the synbiotic product at wk $0(\mathrm{E})$, at wk $6(\mathrm{~F})$, and at wk $12(\mathrm{G})$. 
Table 4. Effect of the supplementation of synbiotic on ratio of cholesterol:phospholipids (mean values $\pm \mathrm{SD}$ ) in red blood cell (RBC) membranes of hypercholesterolemic subjects $(\mathrm{n}=32)$ for $12 \mathrm{wk}$

\begin{tabular}{|c|c|c|c|c|}
\hline \multirow[b]{2}{*}{ Item } & \multirow[b]{2}{*}{ Treatment } & \multicolumn{3}{|c|}{ Week } \\
\hline & & 0 & 6 & 12 \\
\hline Cholesterol (mmol/L per $\left.10^{7} \mathrm{RBC}\right)$ & $\begin{array}{l}\text { Control } \\
\text { Synbiotic }\end{array}$ & $\begin{array}{l}14.00 \pm 2.08^{\mathrm{A}, \mathrm{a}} \\
15.32 \pm 3.03^{\mathrm{A}, \mathrm{a}}\end{array}$ & $\begin{array}{l}14.39 \pm 2.75^{\mathrm{A}, \mathrm{a}} \\
12.82 \pm 2.97^{\mathrm{B}, \mathrm{b}}\end{array}$ & $\begin{array}{l}15.02 \pm 2.62^{\mathrm{A}, \mathrm{a}} \mathrm{a} \\
12.10 \pm 2.57^{\mathrm{B}, \mathrm{c}}\end{array}$ \\
\hline Phospholipids (mmol/L per $10^{7} \mathrm{RBC}$ ) & Control & $9.35 \pm 3.55^{\mathrm{A}, \mathrm{a}}$ & $9.15 \pm 2.16^{\mathrm{A}, \mathrm{a}}$ & $9.15 \pm 2.16^{\mathrm{A}, \mathrm{a}}$ \\
\hline Cholesterol:phospholipids & $\begin{array}{l}\text { Synbiotic } \\
\text { Control } \\
\text { Synbiotic }\end{array}$ & $\begin{array}{l}9.85 \pm 2.89^{\mathrm{A}, \mathrm{a}} \\
1.66 \pm 0.50^{\mathrm{A}, \mathrm{a}} \\
1.68 \pm 0.59^{\mathrm{A}, \mathrm{a}}\end{array}$ & $\begin{array}{r}12.65 \pm 3.14^{\mathrm{B}, \mathrm{b}} \\
1.64 \pm 0.43^{\mathrm{A}, \mathrm{a}} \\
1.05 \pm 0.32^{\mathrm{B}, \mathrm{b}}\end{array}$ & $\begin{aligned} 13.98 & \pm 3.43^{\mathrm{B}, \mathrm{c}} \\
1.73 & \pm 0.42^{\mathrm{A}, \mathrm{a}} \\
0.89 & \pm 0.20^{\mathrm{B}, \mathrm{c}}\end{aligned}$ \\
\hline
\end{tabular}

${ }^{\mathrm{A}, \mathrm{B}}$ Means in the same column with different uppercase superscripts are significantly different $(P<0.05)$.

${ }^{\mathrm{a}-\mathrm{c}}$ Means in the same row with different lowercase superscripts are significantly different $(P<0.05)$.

motion of membrane lipid molecules. Any alterations in membrane fluidity are associated with changes in physiological processes, including carrier-mediated transport, activities of membrane-bound enzymes, and receptor binding (Koike et al., 1998). Data from our present study provided the evidence that the synbiotic product improved membrane fluidity and decreased cholesterol enrichment via alterations of the RBC membrane lipid profiles.

\section{Fluorescence Anisotropy of RBC Membrane}

Considering that cholesterol enrichment occurred within the RBC membrane and changes in lipid profiles occurred, we subsequently determined the location of cholesterol enrichment via FAn using fluorescent probes. The measurement of these fluorescence anisotropies responds to alterations in the membrane fluidity and packing order of the environment surrounding the probe. Any alteration in membrane fluidity changes the rate of probe movement, and the packing order affects the range of possible motion (Stott et al., 2008). A decrease of FAn indicates an increase of membrane fluidity in the region of the bilayer where the probe is located (Gabbianelli et al., 2002).

The synbiotic group showed a significantly $(P<$ $0.05)$ lower FAn of ANS by $18.98 \%$ over $12 \mathrm{wk}$, whereas the control showed insignificant changes (Table 6). The fluorescent probe of ANS is a fluorophore with a high affinity toward the interface between the apolar tail and polar head of phospholipids. The ANS probe binds to phospholipids in which the anionic sulfonate group is oriented toward the hydrophilic head group of the lipid (Marczak, 2009). Changes in the surface have been associated with the insertion of positively charged molecules into the bilayer and thus contribute to an increase in the packing order of the surface and the inner hydrocarbon region. In the present study, the lower FAn of ANS in the synbiotic group showed that the enrichment of cholesterol was reduced in the upper phospholipid region. This condition improved membrane fluidity and reduced the packing order of RBC.

The supplementation of synbiotic also contributed to a significant $(P<0.05)$ reduction of DPH by $19.10 \%$ over $12 \mathrm{wk}$, whereas the control did not show any significant changes (Table 6). The DPH fluorophore is apolar with a high affinity for different hydrophobic regions within the membrane, where it is located preferentially in the hydrocarbon core of lipid bilayer and the position of the anthroyl moiety is on the C-12 of the membrane phospholipids (Sivonová et al., 2004). This probe responds to alterations in the physical properties of the acyl chain region of the membrane phospholipids that affect its ability to rotate (Stott et al., 2008). Changes in DPH values reflect modifications in the physicochemical structure of the inner hydrophobic core (Gabbianelli et al., 2002). In the present study, the lower FAn of DPH in hypercholesterolemic subjects supplemented with synbiotic showed that cholesterol enrichment was decreased within the apolar region of $\mathrm{RBC}$, indicating reduced enrichment of cholesterol in the region close to acyl chains of the phospholipids tails.

The 12-wk supplementation of synbiotic also contributed to a significantly $(P<0.05)$ decreased FAn of TMA-DPH by $15.40 \%$, whereas the control showed insignificant changes (Table 6). The TMA-DPH probe is a cationic derivative of $\mathrm{DPH}$ and is incorporated into the hydrocarbon region near the membrane surface anchoring by its charged group; TMA is incorporated in the head group and DPH incorporated in the acyl chain (Sivonová et al., 2004). The polar region of TMADPH remains anchored at the lipid water interface of the membrane with the hydrocarbon chain entering the lipid part of the membrane (Marczak, 2009). This probe has been associated with reduced water penetrability into the bilayer corresponding with higher cholesterol concentration and a more ordered bilayer structure in the head region. The TMA-DPH probe is localized at the membrane surface in the phospholipid headgroup region (Alleva et al., 1995). Alterations in 
Table 5. Effect of synbiotic product on fatty acid methyl esters (FAME; mean values \pm SD) in red blood cell membranes of hypercholesterolemic subjects $(\mathrm{n}=32)$ for $12 \mathrm{wk}$

\begin{tabular}{|c|c|c|c|c|}
\hline \multirow[b]{2}{*}{ FAME (mg/mL) } & \multirow[b]{2}{*}{ Treatment } & \multicolumn{3}{|c|}{ Week } \\
\hline & & 0 & 6 & 12 \\
\hline \multirow[t]{2}{*}{ Capric acid methyl ester (C10:0) } & Control & $1.14 \pm 0.25$ & $1.13 \pm 0.27$ & $1.12 \pm 0.32$ \\
\hline & Synbiotic & $0.96 \pm 0.22$ & $0.89 \pm 0.24$ & $0.88 \pm 0.15$ \\
\hline \multirow{2}{*}{ Undecanoic acid methyl ester (C11:0) } & Control & $0.65 \pm 0.23$ & $0.65 \pm 0.25$ & $0.65 \pm 0.27$ \\
\hline & Synbiotic & $0.65 \pm 0.17$ & $0.60 \pm 0.10$ & $0.56 \pm 0.14$ \\
\hline \multirow[t]{2}{*}{ Lauric acid methyl ester (C12:0) } & Control & $0.41 \pm 0.17$ & $0.45 \pm 0.15$ & $0.42 \pm 0.13$ \\
\hline & Synbiotic & $0.44 \pm 0.18$ & $0.35 \pm 0.13$ & $0.34 \pm 0.08$ \\
\hline \multirow[t]{2}{*}{ Tridecanoic acid methyl ester (C13:0) } & Control & $0.51 \pm 0.17$ & $0.52 \pm 0.16$ & $0.51 \pm 0.22$ \\
\hline & Synbiotic & $0.55 \pm 0.22$ & $0.49 \pm 0.18$ & $0.45 \pm 0.12$ \\
\hline \multirow[t]{2}{*}{ Myristoleic acid methyl ester (C14:0) } & Control & $0.54 \pm 0.16$ & $0.51 \pm 0.15$ & $0.53 \pm 0.23$ \\
\hline & Synbiotic & $0.54 \pm 0.21$ & $0.47 \pm 0.13$ & $0.36 \pm 0.12$ \\
\hline \multirow{2}{*}{ Pentadecanoic acid methyl ester (C15:0) } & Control & $0.62 \pm 0.16$ & $0.62 \pm 0.24$ & $0.62 \pm 0.21$ \\
\hline & Synbiotic & $0.60 \pm 0.27$ & $0.54 \pm 0.16$ & $0.50 \pm 0.11$ \\
\hline \multirow[t]{2}{*}{ Palmitic acid methyl ester (C16:0) } & Control & $3.72 \pm 1.50$ & $3.70 \pm 1.54$ & $3.88 \pm 1.63$ \\
\hline & Synbiotic & $3.86 \pm 1.22$ & $3.26 \pm 1.49$ & $2.70 \pm 0.84$ \\
\hline \multirow[t]{2}{*}{ Heptadecanoic acid methyl ester (C17:0) } & Control & $0.45 \pm 0.17$ & $0.47 \pm 0.19$ & $0.47 \pm 0.14$ \\
\hline & Synbiotic & $0.47 \pm 0.15$ & $0.42 \pm 0.14$ & $0.38 \pm 0.11$ \\
\hline \multirow[t]{2}{*}{ Stearic acid methyl ester (C18:0) } & Control & $6.00 \pm 2.34$ & $5.42 \pm 2.42$ & $5.38 \pm 2.59$ \\
\hline & Synbiotic & $5.75 \pm 2.41$ & $4.87 \pm 1.60$ & $4.68 \pm 1.22$ \\
\hline \multirow[t]{2}{*}{ Oleic acid methyl ester (C18:1n-9 cis) } & Control & $0.77 \pm 0.08$ & $0.75 \pm 0.11$ & $0.78 \pm 0.18$ \\
\hline & Synbiotic & $0.78 \pm 0.14$ & $0.84 \pm 0.13$ & $0.93 \pm 0.23$ \\
\hline \multirow[t]{2}{*}{ Linolelaidic acid methyl ester (C18:2n-6 trans) } & Control & $3.16 \pm 1.15$ & $3.26 \pm 1.05$ & $3.20 \pm 1.15$ \\
\hline & Synbiotic & $3.17 \pm 0.93$ & $3.58 \pm 1.08$ & $4.19 \pm 0.76$ \\
\hline \multirow[t]{2}{*}{ Linoleic acid methyl ester (C18:2n-6 cis) } & Control & $1.11 \pm 0.29$ & $1.17 \pm 0.29$ & $1.03 \pm 0.20$ \\
\hline & Synbiotic & $1.08 \pm 0.22$ & $1.23 \pm 0.19$ & $1.31 \pm 0.20$ \\
\hline \multirow[t]{2}{*}{ Heneicosanoic acid methyl ester (C21:0) } & Control & $1.10 \pm 0.34$ & $0.97 \pm 0.21$ & $0.93 \pm 0.25$ \\
\hline & Synbiotic & $0.91 \pm 0.36$ & $0.96 \pm 0.38$ & $0.88 \pm 0.31$ \\
\hline \multirow{2}{*}{ Behenic acid methyl ester (C22:0) } & Control & $0.51 \pm 0.17$ & $0.47 \pm 0.16$ & $0.50 \pm 0.17$ \\
\hline & Synbiotic & $0.53 \pm 0.23$ & $0.51 \pm 0.22$ & $0.46 \pm 0.13$ \\
\hline \multirow[t]{2}{*}{ Lignoceric acid methyl ester (C24:0) } & Control & $1.40 \pm 0.37$ & $1.30 \pm 0.37$ & $1.36 \pm 0.42$ \\
\hline & Synbiotic & $1.33 \pm 0.26$ & $1.17 \pm 0.35$ & $1.08 \pm 0.26$ \\
\hline \multirow[t]{2}{*}{ Saturated fatty acids (SFA) } & Control & $17.05 \pm 3.73^{\mathrm{A}, \mathrm{a}}$ & $16.21 \pm 4.12^{\mathrm{A}, \mathrm{a}}$ & $16.37 \pm 4.41^{\mathrm{A}, \mathrm{a}}$ \\
\hline & Synbiotic & $16.59 \pm 3.91^{\mathrm{A}, \mathrm{a}}$ & $14.54 \pm 2.89^{\mathrm{A}, \mathrm{a}}$ & $13.28 \pm 2.01^{\mathrm{B}, \mathrm{b}}$ \\
\hline \multirow[t]{2}{*}{ Unsaturated fatty acids (UFA) } & Control & $5.05 \pm 1.32^{\mathrm{A}, \mathrm{a}}$ & $5.18 \pm 1.00^{\mathrm{A}, \mathrm{a}}$ & $5.01 \pm 1.24^{\mathrm{A}, \mathrm{a}}$ \\
\hline & Synbiotic & $5.03 \pm 1.04^{\mathrm{A}, \mathrm{a}}$ & $5.66 \pm 1.18^{\mathrm{A}, \mathrm{a}}$ & $6.43 \pm 0.72^{\mathrm{B}, \mathrm{b}}$ \\
\hline \multirow[t]{2}{*}{$\mathrm{UFA} / \mathrm{SFA}$} & Control & $0.32 \pm 0.13^{\mathrm{A}, \mathrm{a}}$ & $0.34 \pm 0.12^{\mathrm{A}, \mathrm{a}}$ & $0.32 \pm 0.09^{\mathrm{A}, \mathrm{a}}$ \\
\hline & Synbiotic & $0.32 \pm 0.11^{\mathrm{A}, \mathrm{a}}$ & $0.41 \pm 0.13^{\mathrm{A}, \mathrm{a}}$ & $0.50 \pm 0.11^{\mathrm{B}, \mathrm{b}}$ \\
\hline \multirow{2}{*}{ Total fatty acids (SFA + UFA) } & Control & $22.10 \pm 3.56^{\mathrm{A}, \mathrm{a}}$ & $21.39 \pm 4.06^{\mathrm{A}, \mathrm{a}}$ & $21.38 \pm 4.94^{\mathrm{A}, \mathrm{a}}$ \\
\hline & Synbiotic & $21.62 \pm 3.86^{\mathrm{A}, \mathrm{a}}$ & $20.20 \pm 2.95^{\mathrm{A}, \mathrm{a}}$ & $19.71 \pm 1.97^{\mathrm{A}, \mathrm{a}}$ \\
\hline
\end{tabular}

\footnotetext{
${ }^{\mathrm{A}, \mathrm{B}}$ Means in the same column with different uppercase superscripts are significantly different $(P<0.05)$
}

${ }^{\mathrm{a}, \mathrm{b}}$ Means in the same row with different lowercase superscripts are significantly different $(P<0.05)$.

TMA-DPH values exhibit modifications in the physicochemical structure of more superficial region of the bilayer (Gabbianelli et al., 2002). In the present study, FAn of TMA-DPH in the synbiotic group was reduced, indicating reduced cholesterol enrichment and packing order in the polar heads of the membrane bilayer, leading to increased membrane fluidity at regions near the membrane surface area.

\section{CONCLUSIONS}

Results from our present study provide the clinical evidence that synbiotics could be used to treat or prevent RBC shape irregularities. Our results suggested that the synbiotic decreased cholesterol saturation in the $\mathrm{RBC}$ membrane and thus reduced the ratio of cholesterol:phospholipids, leading to increased membrane fluidity of RBC. An increased ratio of UFA:SFA also supported improved RBC membrane fluidity. The lower FAn of ANS, DPH, and TMA-DPH in the synbiotic group showed that enrichment of cholesterol was decreased in the upper phospholipid region, in the region closed to acyl chains of the phospholipid tails, and in the polar heads of the membrane bilayer, respectively. Results from the present study establish a new potential application of synbiotics in addition to their conventional roles as gut modulators.

\section{ACKNOWLEDGMENTS}

The authors express their appreciation to the eScienceFund Grant (305/PTEKIND/613218) provided 
Table 6. Effect of the supplementation of synbiotic on fluorescence anisotropy (FAn) of red blood cell ghosts in hypercholesterolemic subjects $(\mathrm{n}=32)$ for $12 \mathrm{wk}^{1}$

\begin{tabular}{|c|c|c|c|c|}
\hline \multirow[b]{2}{*}{ Fluorescent probe ${ }^{2}$} & \multirow[b]{2}{*}{ Treatment } & \multicolumn{3}{|c|}{ Week } \\
\hline & & 0 & 6 & 12 \\
\hline ANS & $\begin{array}{l}\text { Control } \\
\text { Synbiotic }\end{array}$ & $\begin{array}{l}0.2655 \pm 0.03^{\mathrm{A}, \mathrm{a}} \\
0.2845 \pm 0.04^{\mathrm{A}, \mathrm{a}}\end{array}$ & $\begin{array}{l}0.2618 \pm 0.02^{\mathrm{A}, \mathrm{a}} \\
0.2349 \pm 0.04^{\mathrm{B}, \mathrm{b}}\end{array}$ & $\begin{array}{l}0.2736 \pm 0.03^{\mathrm{A}, \mathrm{a}} \\
0.2305 \pm 0.04^{\mathrm{B}, \mathrm{c}}\end{array}$ \\
\hline $\mathrm{DPH}$ & Control & $0.2661 \pm 0.03^{\mathrm{A}, \mathrm{a}}$ & $0.2609 \pm 0.02^{\mathrm{A}, \mathrm{a}}$ & $0.2723 \pm 0.03^{\mathrm{A}, \mathrm{a}}$ \\
\hline TMA-DPH & $\begin{array}{l}\text { Synbiotic } \\
\text { Control } \\
\text { Synbiotic }\end{array}$ & $\begin{array}{l}0.2833 \pm 0.04^{\mathrm{A}, \mathrm{a}} \\
0.2650 \pm 0.03^{\mathrm{A}, \mathrm{a}} \\
0.2824 \pm 0.03^{\mathrm{A}, \mathrm{a}}\end{array}$ & $\begin{array}{l}0.2361 \pm 0.04^{\mathrm{B}, \mathrm{b}} \\
0.2589 \pm 0.03^{\mathrm{A}, \mathrm{a}} \\
0.2347 \pm 0.03^{\mathrm{B}, \mathrm{b}}\end{array}$ & $\begin{array}{l}0.2292 \pm 0.04^{\mathrm{B}, \mathrm{c}} \\
0.2774 \pm 0.03^{\mathrm{A}, \mathrm{a}} \\
0.2389 \pm 0.03^{\mathrm{B}, \mathrm{c}}\end{array}$ \\
\hline
\end{tabular}

by MOSTI (Ministry of Science, Technology and Innovation, Putrajaya Wilayah Persekutuan, Malaysia) and Research University (RU) grants (Penang, Malaysia; 1001/PTEKIND/811089 and 1001/PTEKIND/833003), and the Fellowship provided by Universiti Sains Malaysia (Penang, Malaysia). None of the authors had any conflict of interest related to this manuscript.

\section{REFERENCES}

Alleva, R., G. Ferretti, B. Borghit, E. Pignottit, A. Bassit, and G. Curatola. 1995. Physico-chemical properties of membranes of recovered erythrocytes in blood autologous transfusion: A study using fluorescence technique. Transfus. Sci. 16:291-297.

Austin, M. A., C. M. Hutter, R. L. Zimmern, and S. E. Humphries. 2004. Familial hypercholesterolemia and coronary heart disease: A HuGE association review. Am. J. Epidemiol. 160:421-429.

Berlin, E., S. J. Bhathena, D. McClure, and R. C. Peters. 1998. Dietary Menhaden and corn oils and the red blood cell membrane lipid composition and fluidity in hyper- and normocholesterolemic miniature swine. J. Nutr. 128:1421-1428.

Byfield, F. J., H. Aranda-Espinoza, V. G. Romanenko, G. H. Rothblat, and I. Levitan. 2004. Cholesterol depletion increases membrane stiffness of aortic endothelial cells. Biophys. J. 87:3336-3343.

Cassera, M. B., A. M. Silber, and A. M. Gennaro. 2002. Differential effects of cholesterol on acyl chain order in erythrocyte membranes as a function of depth from the surface: An electron paramagnetic resonance (EPR) spin label study. Biophys. Chem. 99:117-127.

Coccia, R., C. Spadaccio, C. Foppoli, M. Perluigi, E. Covino, M. Lusini, and M. Chello. 2007. The effect of simvastatin on erythrocyte membrane fluidity during oxidative stress induced by cardiopulmonary bypass: A randomized controlled study. Clin. Ther. $29: 1706-1717$.

Cooper, R. A., M. H. Leslie, D. Knight, and D. K. Detweiler. 1980. Red cell cholesterol enrichment and spur cell anemia in dogs fed a cholesterol-enriched, atherogenic diet. J. Lipid Res. 21:10821089.

Dwight, J. F., A. C. Mendes Ribeiro, and B. M. Hendry. 1996. Effects of HMG-CoA reductase inhibition on erythrocyte membrane cholesterol and acyl chain composition. Clin. Chim. Acta 256:5363.

Dykstra, M. J. 1992. Biological Electron Microscopy, Theory, Techniques and Troubleshooting. Plenum Press, New York, NY.

FAO/WHO. 2001. Health and nutritional properties of probiotics in food including powder milk with live lactic acid bacteria. Report of a joint $\mathrm{FAO} / \mathrm{WHO}$ expert consultation on evaluation of health and nutritional properties of probiotics in food including powder milk with live lactic acid bacteria. http://www.who.int/foodsafety/publications/fs_management/probiotics/en/ Accessed Mar. 2, 2010)

Gabbianelli, R., G. Falcioni, C. Nasuti, and F. Cantalamessa. 2002. Cypermethrin-induced plasma membrane perturbation on erythrocytes from rats: Reduction of fluidity in the hydrophobic core and in glutathione peroxidase activity. Toxicology 175:91-101.

Galdeano, C. M., A. de M. de LeBlanc, G. Vinderola, M. E. B. Bonet, and G. Perdigón. 2007. Proposed model: Mechanisms of immunomodulation induced by probiotic bacteria. Clin. Vaccine Immunol. $14: 485-492$

Glauert, A. M. 1980. Fixation, dehydration and embedding of biological specimens. Pages 1-207 in Practical Methods in Electron Microscopy. A. M. Glauert, ed. North-Holland Publishing Co., Amsterdam, the Netherlands.

Hirayama, K., and J. Rafter. 2000. The role of probiotic bacteria in cancer prevention. Microbes Infect. 2:681-686.

Huel, G., J. Sahuquillo, G. Debotte, J.-F. Oury, and L. Takser. 2008. Hair mercury negatively correlates with calcium pump activity in human term newborns and their mothers at delivery. Environ. Health Perspect. 116:263-267.

Hui, S. W., C. M. Stewart, M. P. Carpenter, and T. P. Stewart. 1980. Effects of cholesterol on lipid organization in human erythrocyte membrane. J. Cell Biol. 85:283-291.

Kang, J. X., and J.-D. Wang. 2005. A simplified method for analysis of polyunsaturated fatty acids. BMC Biochem. 6:5.

Keddad, K., P. Thérond, C. Motta, C. Baussan, and A. Legrand. 1996. Alterations in erythrocyte membrane fluidity and fatty acid composition in glycogen storage disease. Biochim. Biophys. Acta Molecular Basis of Disease 1315:61-65.

Kirk, R. E. 1968. Split-plot design: Factorial design with block-treatment confounding. Pages 245-318 in Experimental Design: Procedures for the Behavioral Sciences. Brooks/Cole Publishing Company, a division of Wadsworth Publishing Company Inc., Belmont, CA.

Klinder, A., A. Forster, G. Caderni, A. P. Femia, and B. L. Pool-Zobel. 2004. Fecal water genotoxicity is predictive of tumor-preventive activities by inulin-like oligofructoses, probiotics (Lactobacillus rhamnosus and Bifidobacterium lactis) and their synbiotic combination. Nutr. Cancer 49:144-155.

Koike, T., G. Ishida, M. Taniguchi, K. Higaki, Y. Ayaki, M. Saito, Y. Sakakihara, M. Iwamori, and K. Ohno. 1998. Decreased membrane fluidity and unsaturated fatty acids in Niemann-Pick disease type C fibroblasts. Biochim. Biophys. Acta Molecular Basis of Disease 1406:327-335.

Koter, M., I. Franiak, K. Strychalska, M. Broncel, and J. ChojnowskaJezierska. 2004. Damage to the structure of erythrocyte plasma membranes in patients with type-2 hypercholesterolemia. Int. J. Biochem. Cell Biol. 36:205-215. 
Liong, M. T., F. R. Dunshea, and N. P. Shah. 2007. Effects of a synbiotic containing Lactobacillus acidophilus ATCC 4962 on plasma lipid profiles and morphology of erythrocytes in hypercholesterolemic pigs on high- and low-fat diets. Br. J. Nutr. 98:736-744.

Liong, M. T., and N. P. Shah. 2006. Effects of a Lactobacillus casei synbiotic on serum lipoprotein, intestinal microflora, and organic acids in rats. J. Dairy Sci. 89:1390-1399.

López-Revuelta, A., J. I. Sánchez-Gallego, A. C. García-Montero, A. Hernández-Hernández, J. Sánchez-Yagüe, and M. Llanillo. 2007. Membrane cholesterol in the regulation of aminophospholipid asymmetry and phagocytosis in oxidized erythrocytes. Free Radic. Biol. Med. 42:1106-1118.

López-Revuelta, A., J. I. Sánchez-Gallego, A. Hernández-Hernández, J. Sánchez-Yagüe, and M. Llanillo. 2005. Increase in vulnerability to oxidative damage in cholesterol-modified erythrocytes exposed to t-BuOOH. Biochim. Biophys. Acta Molecular Cell Biol. Lipids 1734:74-85.

Marczak, A. 2009. Fluorescence anisotropy of membrane fluidity probes in human erythrocytes incubated with anthracyclines and glutaraldehyde. Bioelectrochemistry 74:236-239.

Martínez, M., A. Vayá, R. Martí, L. Gil, I. Lluch, R. Carmena, and J. Aznar. 1996. Erythrocyte membrane cholesterol/phospholipid changes and hemorheological modifications in familial hypercholesterolemia treated with lovastatin. Thromb. Res. 83:375-388.

McDowell, E. M., and B. F. Trump. 1976. Histologic fixatives suitable for diagnostic light and electron microscopy. Arch. Pathol. Lab. Med. 100:405-414.

Mohandas, N., and P. G. Gallagher. 2008. Red cell membrane: Past, present, and future. Blood 112:3939-3948.

Nation, J. L. 1983. A new method using hexamethyldisilazane for preparation of soft insect tissues for scanning electron microscopy. Stain Technol. 58:347-351.

Nayak, B. S., V. Y. Beharry, S. Armoogam, M. Nancoo, K. Ramadhin K. Ramesar, C. Ramnarline, A. Singh, A. Singh, K. U. Nwachi, S. Teelucksing, R. Mathura, and L. Roberts. 2008. Determination of $\mathrm{RBC}$ membrane and serum lipid composition in Trinidadian type II diabetics with and without nephropathy. Vasc. Health Risk Manag. 4:893-899.

Neuhouser, M. L., D. L. Miller, A. R. Kristal, M. J. Barnett, and L. J. Cheskin. 2002. Diet and exercise habits of patients with diabetes, dyslipidemia, cardiovascular disease or hypertension. J. Am. Coll. Nutr. 21:394-401.

Nguyen, T. D. T., J. H. Kang, and M. S. Lee. 2007. Characterization of Lactobacillus plantarum $\mathrm{PH} 04$, a potential probiotic bacterium with cholesterol-lowering effects. Int. J. Food Microbiol. 113:358-361

Ooi, L. G., R. Ahmad, K. H. Yuen, and M. T. Liong. 2010. Hypocholesterolemic effects of probiotic-fermented dairy products. Milchwissenschaft (in press)

Reddy, K. S., and S. Yusuf. 1998. Emerging epidemic of cardiovascular disease in developing countries. Circulation 97:596-601.

Roberfroid, M. 2007. Prebiotics: The concept revisited. J. Nutr. 137:830S-837S.

Schley, P. D., and C. J. Field. 2002. The immune-enhancing effects of dietary fiber and prebiotics. Br. J. Nutr. 87:221-230.
Scholz-Ahrens, K. E., P. Ade, B. Marten, P. Weber, W. Timm, Y Asil, C.-C. Glüer, and J. Schrezenmeir. 2007. Prebiotics, probiotics and synbiotics affect mineral absorption, bone mineral content and bone structure. J. Nutr. 137:838S-846S.

Shanmugasundaram, K. R., A. Visvanathan, K. Dhandapani, N. Srinivasan, P. Rasappan, R. Gilbert, S. Alladi, S. Kancharla, and N Vasanthi. 1986. Effect of high-fat diet on cholesterol distribution in plasma lipoproteins, cholesterol esterifying activity in leucocytes, and erythrocyte membrane components studied: Importance of body weight. Am. J. Clin. Nutr. 44:805-815.

Sivonová, M., I. Waczulíková, E. Kilanczyk, M. Hrnčiarová, M. Bryszewska, B. Klajnert, and Z. Duračková. 2004. The effect of Pycnogenol ${ }^{\circledR}$ on the erythrocyte membrane fluidity. Gen. Physiol. Biophys. 23:39-51.

Stott, B. M., M. P. Vu, C. O. McLemore, M. S. Lund, E. Gibbons, T. J. Brueseke, H. A. Wilson-Ashworth, and J. D. Bell. 2008. Use of fluorescence to determine the effects of cholesterol on lipid behavior in sphingomyelin liposomes and erythrocyte membranes. J. Lipid Res. 49:1202-1215.

Tee, E. S., M. I. Noor, M. N. Azudin, and K. Idris, 1997. Nutrient Composition of Malaysian Foods. 4th ed. Institute for Medical Research (for the Malaysian Food Composition Database Programme), Kuala Lumpur, Malaysia.

Torkhovskaia, T. I., E. M. Khalilov, E. S. Fortinskaia, Zh. I. Kliuchnikova, and L. K. Ryzhkova. 1985. Effect of the plasma lipoprotein spectrum on the cholesterol level in erythrocyte membranes. Vopr. Med. Khim. 31:83-87.

Tsuzuki, D., K. Sumino, and M. Yokoyama. 2000. Analysis of 7-ketocholesterol in low density lipoprotein and fatty acid composition in erythrocyte membranes of patients on maintenance hemodialysis and healthy controls. Clin. Chim. Acta 295:155-168.

van Gelder, J. M., C. H. Nair, and D. P. Dhall. 1996. Erythrocyte aggregation and erythrocyte deformability modify the permeability of erythrocyte enriched fibrin network. Thromb. Res. 82:33-42.

Waldeck, A. R., M. H. Nouri-Sorkhabi, D. R. Sullivan, and P. W. Kuchel. 1995. Effects of cholesterol on transmembrane water diffusion in human erythrocytes measured using pulsed field gradient NMR. Biophys. Chem. 55:197-208.

WHO. 2003. Cardiovascular disease: Prevention and control (online). http://www.who.int/dietphysicalactivity/publications/facts/cvd/ en/ Accessed Mar. 23, 2010.

Wong, J. M. W., C. W. C. Kendall, R. de Souza, A. Emam, A. Marchie, E. Vidgen, C. Holmes, and D. J. A. Jenkins. 2010. The effect on the blood lipid profile of soy foods combined with a prebiotic: A randomized controlled trial. Metabolism In press.

Yeo, S. K., and M. T. Liong. 2010. Angiotensin I-converting enzyme inhibitory activity and bioconversion of isoflavones by probiotics in soymilk supplemented with prebiotics. Int. J. Food Sci. Nutr. 61:161-181.

Zhang, F., X.-M. Hang, X.-B. Fan, G.-J. Li, and H. Yang. 2007. Selection and optimization procedure of synbiotic for cholesterol removal. Anaerobe 13:185-192. 